\title{
EFEKTIFITAS MEKANISME TATA KELOLA TEKNOLOGI INFORMASI TERHADAP INOVASI TI DAN KINERJA TI
}

\author{
Anwar Fattah ${ }^{1)}$, Resad Setyadi ${ }^{2}$ \\ ${ }^{1}$ Teknik Elektro, Universitas Balikpapan \\ ${ }^{2}$ Sistem Informasi, Universitas Bung Karno \\ E-mail : ${ }^{1}$ anwar.fattah@gmail.com, ${ }^{2}$ resad.setyadi@gmail.com
}

\begin{abstract}
Information technology supports the achievement of business objectives in the organization. Higher education institutions is a business organization engaged in the field of education, research and devotion to the society in the Know Tridharma College. Effective IT governance ensures the alignment between IT and the business objectives. The study seeks to examin empirically IT governance mechanisms affecting the overall effectiveness of IT governance. In addition, this study examines effective IT governance relationships and IT performance in higher education organizations. The sampling techniques in this study are multi-stage purposeful random sampling. In order, the researchers will incorporate the surveys online. Analyzed by Quantitative Data and method of a Partial Least Squares (PLS-SEM) equation using Smart PLS 3.0. The results obtained from this research show significant positive relationships between effectiveness IT governance and the following mechanisms: IT steering Committee, senior management involvement in IT, and organizational communication systems and relationships between the effectiveness of ITG with IT innovation and IT performance. And insignificant negative relationship between organizational Performance management system and effectiness IT Governance also IT Innovation and IT Performance
\end{abstract}

Keywords : IT Governance, Effectiveness IT, ITG mechanism

\section{INTISARI}

Teknologi informasi mendukung pencapaian tujuan bisnis pada organisasi. Lembaga pendidikan tinggi adalah sebuah organisasi bisnis yang bergerak di bidang pendidikan, penelitian dan pengabdian kepada masyarakat yang di kenal tridharma perguruan tinggi. Tata kelola TI yang efektif akan memastikan keselarasan antara TI dan tujuan bisnis.. Studi ini berusaha untuk memeriksa secara empiris mekanisme tata kelola TI yang mempengaruhi efektivitas keseluruhan Tata Kelola TI. Selain itu, penelitian ini mengkaji hubungan tata kelola TI yang efektif dan Kinerja TI dalam organisasi pendidikan tinggi. Teknik sampling yang Akan dilakukan dalam penelitian ini adalah multi-stage purposeful random sampling. Secara berurutan, para peneliti Akan menggabungkan survei melalui online. Data kuantitatif dianalisis dengan metode persamaan Partial Least Squares (PLS-SEM) menggunakan Smart PLS 3.0. Hasil yang Diperoleh dari penelitian ini menunjukkan hubungan positif yang signifikan antara tata kelola TI yang efektif dan mekanisme berikut: IT steering Committee, keterlibatan manajemen senior di IT, dan sistem komunikasi organisaasi serta hubungan positif antara efektivitas ITG dengan Inovasi TI serta Kinerja TI. Dan tidak ada hubungan antara Sistem pengukuran kinerja organisasi dengan efektivitas tata kelola teknologi informasi (TI). Serta Inovasi TI dengan Kinerja TI

Kata Kunci : Tata kelola TI, Efektivitas TI, Mekanisme ITG 


\section{PENDAHULUAN}

Lembaga pendidikan tinggi, khususnya Universitas dari berbagai negara, telah mengakui semakin pentingnya aspek Tata Kelola teknologi Informasi (TI) [1]. Penggunaan Teknologi Informasi (TI) yang secara efektif dan efisien di Universitas beguna dalam mendukung riset, pengajaran, dan manajemen memerlukan Tata Kelola IT yang tepat [2][3][4][5]. Tata Kelola TI yang efektif di Universitas sangat berkaitan dengan mekanisme tata kelola Teknologi Informasi (TI). Selain itu, adopsi praktek formal mekanisme tata kelola TI pada tingkat tertinggi pada suatu organisasi dalam hal ini pada level manajemen dalam mengatur TI, menurut peneliti [6][7] diharapkan membawa manfaat dan meningkatkan kinerja organisasi.

Untuk mengontrol teknologi informasi (TI) di perguruan tinggi maka tata kelola TI yang efektif sangat penting dalam membuat penggunaan struktur, proses, dan hubungan mekanisme Menurut [4], Organisasi yang kompleks dan terdesentralisasi, seperti Universitas, harus sering meninjau mekanisme tata kelola Teknologi Informasi (TI) mereka untuk melakukan inovasi dan perubahan dalam lingkungan mereka dan beradaptasi dengan teknologi baru. Kerangka tata kelola Teknologi informasi (TI) dapat digunakan dengan seperangkat mekanisme seperti struktur, proses, dan hubungan mekanisme [8][9][10] [11].

Di samping itu Tata kelola teknologi informasi (TI) yang efektif sangat penting bagi sebuah organisasi untuk mencapai tujuan kinerja organisasi..Untuk menerapkan tata kelola teknologi informasi (TI) secara efektif di perlukan seperangkat mekanisme tata kelola TI (mis., Komite Pengarah TI, struktur organisasi TI) yang mendorong perilaku organisasi selaras dengan misi, strategi, nilai, norma, dan budaya organisasi [12][7].

Pada penelitian sebelumnya tentang efektivitas mekanisme tata kelola TI telah menghasilkan hasil penelitian tentang bagaimana mekanisme individu tata kelola TI berpengaruh terhadap effektifitas tata kelola teknologi informasi [13][12][11].

Sebuah mekanisme yang mungkin cocok untuk sebuah organisasi dalam industri keuangan mungkin tidak cocok untuk sebuah organisasi di industri lain [14][15][16]. Pada penelitian sebelumnya peneliti mengidentifikasi dasar dari mekanisme tata kelola TI untuk industri keuangan Belgia. [17]. Dan mekanisme tata kelola teknologi informasi (TI) untuk industri keuangan dan pada industri kesehatan [18]. Hasil ini menunjukkan bahwa mekanisme tata kelola TI berbeda di seluruh sektor industri. Kebutuhan dalam menganalisis mekanisme tata kelola teknologi informasi (TI) yang efektif dalam konteks yang berbeda mendorong studi lebih lanjut terutama pada sector pendidikan tinggi.

\section{PENDEKATAN PEMECAHAN MASALAH}

\section{Metode}

Metode Penelitian pada studi ini menggunakan kuantitatif dimana data yang berasal dari studi literature yang diperoleh kemudian dikembangkan menjadi kuesioner. Kuesioner survei ini dipilih karena dianggap sebagai teknik yang paling disukai karena banyak keuntungan dan kualitas baik [19]. Teknik sampling dari studi ini adalah multi-stage purposeful random sampling. Dalam fase pengumpulan data kuantitatif, kuesioner Google Docs dikirim secara acak melalui email, sedangkan kuesioner berbasis Online didistribusikan langsung melalui Google Form ke stakeholder institusi perguran tinggi negeri (PTN) dan Perguruan tinggi swasta (PTS) seluruh indonesia dalam hal ini kalangan struktural perguruan tinggi, dosen serta staf kependidikan. Dari kuisioner yang masuk sebanyak 100 responden, melalui proses seleksi dan kelayakan yang diambil hanya 92 respoden (92\%).

Untuk memenuhi kelayakan mutu, data ini kemudian dianalisis dengan mempertimbangkan nilainya: Cronbach Alpha (0,6), Composite Realibility $(0,7)$, AVE $(0,5)$ dan Factor Loading $(0,7)$ [20][21] Untuk menentukan tingkat besar jalur koefisien bootstrap dan T-Statistik proses yang digunakan di atas 1,98 di 95\% Interval tingkat kepercayaan.

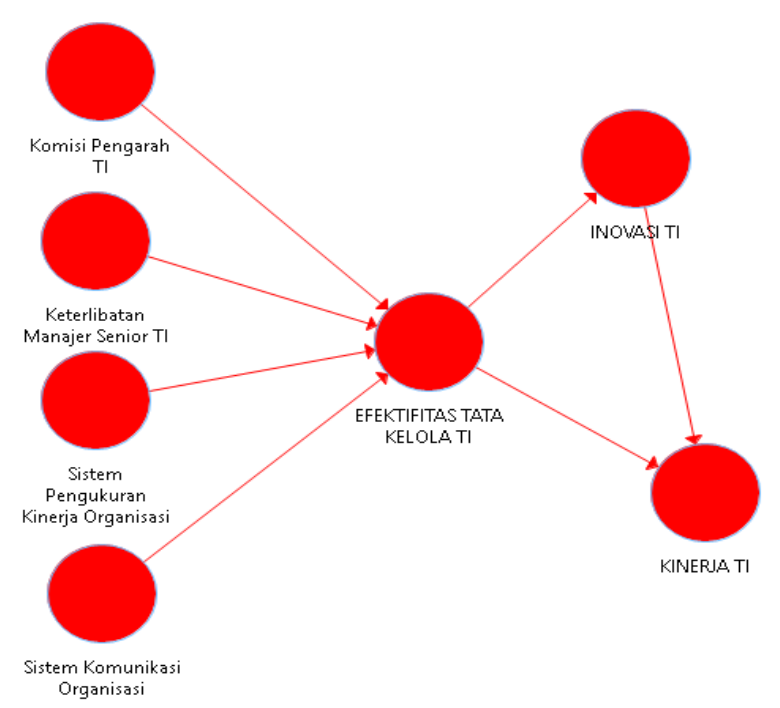

Gambar 1. Model Penelitian 
Model penelitian dapat dilihat pada gambar. 1. Model penelitian merupakan adopsi dari model evaluasi tata kelola TI yang digunakan oleh pada organisasi di lembaga pendidikan tinggi (HEI) [22]. Pada model ini diidentifikasi faktor-faktor mekanisme tata kelola teknologi informasi (TI) yang berkontribusi pada efektifitas tata kelola teknologi informasi (TI) .yaitu: Komisi pengarah TI, keterlibatan senior manager TI, sistem pengukuran kinerja organisasi dan sistem komunikasi organisaasi. Penulis mengembangkan model hubungan antara efektif TI tata kelola TI, inovasi IT dan kinerja TI.

Berdasarkan hasil pengolahan data menggunakan smart PLS di peroleh hasil yang ditunjukan pada gambar 2 di bawah ini.

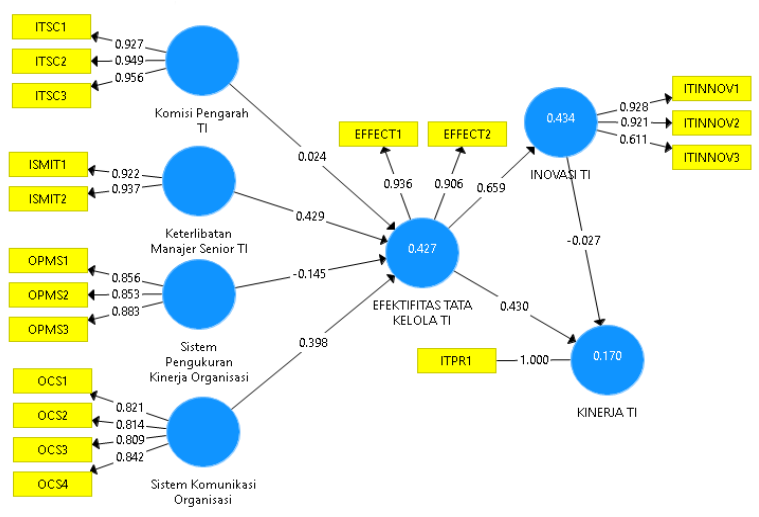

Gambar 2. Hasil Pengukuran Model

\section{HASIL DAN PEMBAHASAN}

Model yang diusulkan oleh peneliti harus diuji validitasnya dari model yang diusulkan dan untuk menentukan apakah data, yang telah dikumpulkan di lapangan, cocok dengan model konseptual yang diusulkan. Kualitas model pengukuran ditentukan berdasarkan validitas dan reliabilitasnya [20][21]. Hasilnya validitas dan reliabilitas data ditunjukkan pada Tabel 1.

Tabel 1. Penilaian Akurasi Pengukuran

\begin{tabular}{|c|c|c|c|c|c|}
\hline $\begin{array}{l}\text { Research } \\
\text { Constructs }\end{array}$ & $\begin{array}{l}\text { PLS } \\
\text { code item }\end{array}$ & $\begin{array}{l}\text { Cronbach's Alpha } \\
\text { Value }\end{array}$ & $\begin{array}{l}\text { Composite } \\
\text { reliability }\end{array}$ & $\begin{array}{l}\text { Average variance } \\
\text { extracted (AVE) }\end{array}$ & Factor loading \\
\hline \multirow[t]{3}{*}{ ITSC } & ITSC1 & 0.939 & 0.961 & 0.891 & 0.927 \\
\hline & ITSC2 & & & & 0.949 \\
\hline & ITSC3 & & & & 0.956 \\
\hline \multirow[t]{2}{*}{ ISMIT } & ISMIT1 & 0.843 & 0.927 & 0.864 & 0.922 \\
\hline & ISMIT2 & & & & 0.937 \\
\hline \multirow[t]{3}{*}{ OPMS } & OPMS1 & 0.830 & 0.898 & 0.746 & 0.856 \\
\hline & OPMS2 & & & & 0.853 \\
\hline & OPMS3 & & & & 0.883 \\
\hline \multirow[t]{4}{*}{ OCS } & OCS1 & 0.842 & 0.897 & 0.675 & 0.821 \\
\hline & OCS2 & & & & 0.814 \\
\hline & OCS3 & & & & 0.842 \\
\hline & OCS4 & & & & 0.842 \\
\hline \multirow[t]{2}{*}{ ITG EFFECT } & EFFECT1 & 0.822 & 0.918 & 0.848 & 0.936 \\
\hline & EFFECT2 & & & & 0.906 \\
\hline \multirow[t]{3}{*}{ ITINNOV } & ITINNOV1 & 0.770 & 0.870 & 0.695 & 0.928 \\
\hline & ITINNOV2 & & & & 0.921 \\
\hline & ITINNOV3 & & & & 0.611 \\
\hline ITPR & ITPR1 & 1.000 & 1.000 & 1.000 & 1.000 \\
\hline
\end{tabular}


JTID http://tip.ppj.unp.ac.id

Tabel 2. Hasil Analisis SEM

\begin{tabular}{lllll}
\hline Path & Hypothesis & $\begin{array}{l}\text { Pathcoefficient } \\
(\beta)\end{array}$ & T-Statistic & Decision \\
\hline ITSC ->ITG Effect & H1 (+) & 0.024 & 0.180 & Positive and tidak signifikan \\
ISMIT -> ITG Effect & H2 (+) & 0.429 & 3.435 & Positif dan signifikan \\
OPMS -> ITG Effect & H3 (+) & -0.145 & 0.863 & Negatif dan tidak signifikan \\
OCS -> ITG Effect & H4 (+) & 0.390 & 2.421 & Positif dan signifikan \\
ITG Effect -> ITINNOV & H5 (+) & 0.659 & 5.404 & Positif dan signifikan \\
ITGEffect - > IT PERF & H6 (+) & 0.430 & 3.717 & Positif dan signifikan \\
TG Innov- > IT PERF & H7 (+) & -0.027 & 0.198 & Negatif dan tidak signifikan \\
\hline
\end{tabular}

Berdasarkan Tabel 1 dan Tabel 2, diperoleh hasil bahwa efektifitas tata kelola teknologi informasi berpengaruh secara signifikan terhadap kinerja TI. Sementara Inovasi TI tidak berpengaruh terhadap kinerja TI. Untuk mekanisme indivisu tata kelola Teknologi informasi. Komite Pengarah TI, keterlibatan Senior Manajer TI, Sistem komunikasi organisasi berpengauh terhadap Efektivitas teta kelola.

\section{KESIMPULAN}

Berdasarkan hasil penelitian bahwa Komite Pengarah TI, keterlibatan senior manajer TI, Sistem komunikasi organisasi berpengauh terhadap Efektivitas teta kelola TI serta Efektifitas tata kelola teknologi informasi sangat berpengaruh terhadap Inovasi TI dan Kinerja TI. Sementara terkait dengan sistem pengukuran kinerja organisasi tidak perpengaruh terhadap efektivitas tata kelola TI. Terkait studi hubungan antara Inovasi TI tidak berpengaruh langsung terhadap kinerja TI.

\section{DAFTAR PUSTAKA}

[1] P. Subsermsri, K. Jairak, and P. Praneetpolgrang, "Information technology governance practices based on sufficiency economy philosophy in the thai university sector", Inf. Technol. People, 2015.

[2] N. Bajgoric, "Business continuity management: A systemic framework for implementation," Kybernetes, 2014.

[3] I. S. Bianchi and R. D. Sousa, "IT Governance Mechanisms in Higher Education", in Procedia Computer Science, 2016.
[4] M. Hicks, G. Pervan, and B. Perrin, "A study of the review and improvement of IT governance in Australian universities in Australian universities", Int. Conf. Inf. Resour. Manag, 2012.

[5] S. P. J. Wu, D. W. Straub, and T. P. Liang, "How information technology governance mechanisms and strategic alignment influence organizational performance: Insights from a matched survey of business and it managers", MIS Q. Manag. Inf. Syst., 2015.

[6] G. L. Lunardi, J. L. Becker, A. C. G. Maçada, and P. C. Dolci, "The impact of adopting IT governance on financial performance: An empirical analysis among Brazilian firms", Int. J. Account. Inf. Syst., 2014.

[7] W. Peter and R. Jeanne, "A Matrixed Approach to Designing IT Governance", MIT Sloan Manag. Rev., 2005.

[8] S. De Haes and W. Van Grembergen, "IT Governance and its Mechanisms", Inf. Syst. Control J., 2004.

[9] W. Van Grembergen, S. De Haes, and E. Guldentops, "Structures, Processes and Relational Mechanisms for IT Governance", in Strategies for Information Technology Governance, 2011.

[10] R. Peterson, "Crafting information technology governance”, Inf. Syst. Manag., 2004.

[11] J. W. Ross and P. Weill, "How Top Performers Manage IT Decisions Rights for Superior Results", IT Gov., 2004. 
[12] C. Ferguson, P. Green, R. Vaswani, and G. $\mathrm{Wu}$, "Determinants of Effective Information Technology Governance", Int. J. Audit., 2013.

[13] S. Ali and P. Green, "Effective information technology (IT) governance mechanisms: An IT outsourcing perspective", Inf. Syst. Front., 2012.

[14] A. E. Brown and G. G. Grant, "Framing the Frameworks: A Review of IT Governance Research", Commun. Assoc. Inf. Syst., 2005.

[15] S. De Haes, W. Van Grembergen, and R. S. Debreceny, "COBIT 5 and enterprise governance of information technology: Building blocks and research opportunities", J. Inf. Syst., 2013.

[16] W. Van Grembergen, "IT governance and its mechanisms", Proceedings of the Annual Hawaii International Conference on System Sciences, 2006.

[17] R. Pereira, R. Almeida, and M. M. Da Silva, "IT governance patterns in the portuguese financial industry", Proceedings of the Annual Hawaii International Conference on System Sciences, 2014.
[18] R. Pereira, M. Mira da Silva, and L. V. Lapão, "Business/IT Alignment through IT Governance Patterns in Portuguese Healthcare," Int. J. It/bus. Alignment Gov., 2014.

[19] A. Shuhaiber, "The role of perceived control, enjoyment, cost, sustainability and trust on intention to use smart meters: An empirical study using SEM-PLS", in Advances in Intelligent Systems and Computing, 2018.

[20] F. Quoquab, S. Pahlevan, J. Mohammad, and R. Thurasamy, "Factors affecting consumers' intention to purchase counterfeit product", Asia Pacific J. Mark. Logist., 2017.

[21] C. M. Ringle, M. Sarstedt, and D. W. Straub, "A critical look at the use of PLS-SEM in MIS quarterly", MIS Quarterly: Management Information Systems. 2012.

[22] M. Q. Huda, M. C. Utami, N. A. Hidayah, and Q. Aini, "Effective IT Governance in Higher Education Institutions: The Conceptual Model", 2018. 